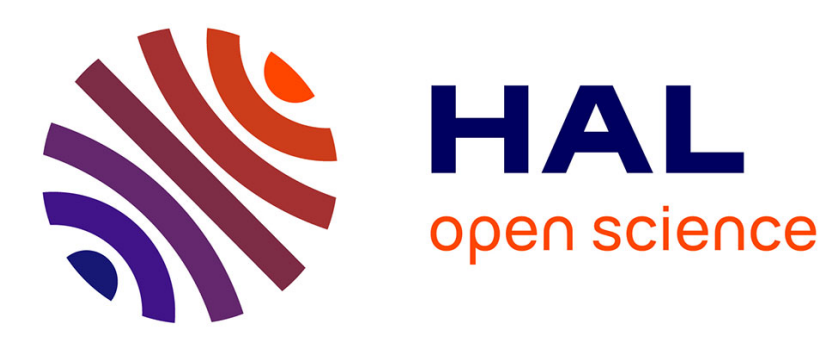

\title{
Fatigue Behavior of Polyamide 66/Glass Fiber Under Various Kinds of Applied Load
}

\author{
B Esmaeillou, P Ferreira, V Bellenger, A Tcharkhtchi
}

\section{To cite this version:}

B Esmaeillou, P Ferreira, V Bellenger, A Tcharkhtchi. Fatigue Behavior of Polyamide 66/Glass Fiber Under Various Kinds of Applied Load. Polymer Composites, 2012, 33, pp.540-547. 10.1002/pc.22185 . hal-01202696

\section{HAL Id: hal-01202696 https://hal.science/hal-01202696}

Submitted on 21 Sep 2015

HAL is a multi-disciplinary open access archive for the deposit and dissemination of scientific research documents, whether they are published or not. The documents may come from teaching and research institutions in France or abroad, or from public or private research centers.
L'archive ouverte pluridisciplinaire HAL, est destinée au dépôt et à la diffusion de documents scientifiques de niveau recherche, publiés ou non, émanant des établissements d'enseignement et de recherche français ou étrangers, des laboratoires publics ou privés. 


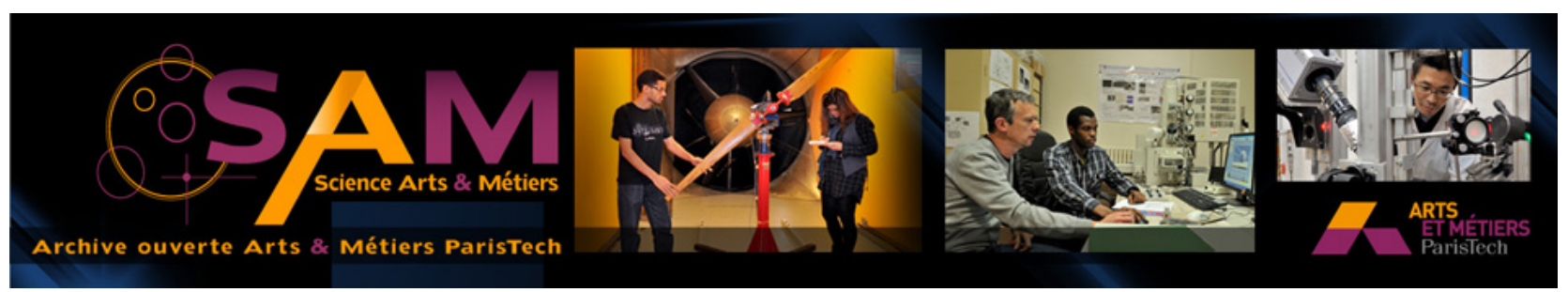

\section{Science Arts \& Métiers (SAM)}

is an open access repository that collects the work of Arts et Métiers ParisTech researchers and makes it freely available over the web where possible.

This is an author-deposited version published in: http://sam.ensam.eu

Handle ID: .http://hdl.handle.net/10985/10081

\section{To cite this version :}

B ESMAEILLOU, P FERREIRA, V BELLENGER, A TCHARKHTCHI - Fatigue Behavior of Polyamide 66/Glass Fiber Under Various Kinds of Applied Load - Polymer Composites - Vol. 33, p.540-547 - 2012 


\title{
Fatigue Behavior of Polyamide 66/Glass Fiber Under Various Kinds of Applied Load
}

\author{
B. Esmaeillou, P. Ferreira, V. Bellenger, A. Tcharkhtchi \\ Laboratoire Procédé d'Ingénierie Mécanique et Matériaux (PIMM)-Arts et Métiers ParisTech, Paris, France
}

\begin{abstract}
In this study, the fatigue behavior of polyamide 66 reinforced with short glass fibers and especially the role of glass fibers has been investigated under two kinds of cyclic loading. tension-tension fatigue tests with stress controlled and alternative flexural fatigue test with strain controlled were carried out. The main topics include microscope damage observation, described by fiber/matrix debonding and interfacial failure, endurance limit with Wohler curves, effect of self-heating temperature. For both tests, the surface temperature increases with an increasing applied load. The results show that the self-heating has an important effect in the failure point where the Wohler curves join each other. The fracture surface was analyzed by scanning electron microscope for both applied loads. The stress ratio is -1 for alternative flexural fatigue test and 0.1 and $\mathbf{0 . 3}$ for tension-tension fatigue test ones at frequencies ranging 2-60 Hz. POLYM. COMPOS., 33:540-547, 2012. (๑) 2012 Society of Plastics Engineers
\end{abstract}

\section{INTRODUCTION}

Nowadays, the industry is strongly demanding data on fatigue behavior of polymers particularly reinforced polymers because of their good performance. The main reasons are economical price and low density that could help to save energy and reduce greenhouse gas emissions [14]. Glass fibers reinforced polyamides have many applications in automotives parts (under hood, engine air intake manifold, cooling fan housing), railway industry (train compound, railway tie insulators), safety parts in sports (some parts of snowboard), and electrical parts (connectivity). These composites are usually known for their high stiffness and resistance in fatigue [2].

There are several parameters that affect the fatigue behavior of glass fibers reinforced polyamides composites such as:

- Manufacturing process (skin-core morphology of the polymer matrix, orientation, and concentration of the fibers).
- Environmental conditions (moisture, temperature, oxygen, and UV).

- Parameters that are related to the materials such as matrix nature, percentage of the fibers, fiber length, and strength of the fiber/matrix interface resistance between fiber and matrix nature [5-10].

A strong chemical bonding between fiber and matrix leads to a rather good improvement of thermal or static mechanical properties [11].

The applied parameters such as loading amplitude and frequency could also affect the fatigue behavior, for instance in a fatigue test, crack propagation rate depends on the loading level and frequency. At frequencies below $1 \mathrm{~Hz}$ and room temperature, the mechanism of crack propagation is very low. By increasing the frequency, the molecular motion will increase and self-heating phenomenon will occur, resulting from energy dissipation [12, 13].

Handa et al. [14] compared frequencies from 5 to 50 $\mathrm{Hz}$ and observed that increasing the frequency decreases the fatigue life time. Zhou and Mallick [7] studied the influence of frequency during the fatigue test of nylon 66 reinforced with $30 \%$ glass fibers and concluded that for the frequency $>2 \mathrm{~Hz}$, the progressive increase in the frequency decreases the life time.

Horst and Spoormaker [15] showed that for polyamide 6 reinforced with 30\% glass fiber, temperature increases even at a frequency of $1 \mathrm{~Hz}$. They demonstrated that for lower frequencies, creep has a negative effect on life time.

By increasing the frequency, the molecular motion will increase, and hence we will have self-heating phenomenon, owing to the energy dissipation. Self-heating temperature can decrease the fatigue life time [16].

Kajiyama and Takahara [17] have demonstrated the dependence of temperature rise to frequency and stress level with the following equations:

$$
H_{\mathrm{T}}=\pi f E^{\prime \prime}{ }_{\mathrm{nl}} \varepsilon_{\mathrm{av}}^{2}
$$

where $H_{\mathrm{T}}$ is hysteresis loss, $\varepsilon_{\mathrm{av}}$ is average strain, $f$ is frequency, and $E^{\prime \prime}{ }_{n l}$ is the nonlinear loss modulus. Supposing that: 


$$
\varepsilon_{\mathrm{av}}=\frac{\varepsilon_{\mathrm{max}}}{2}=\frac{\sigma_{\mathrm{max}} / 2}{E}
$$

and $E \approx E^{\prime}$, the $E q .1$ becomes:

$$
H_{\mathrm{T}}=\pi f E^{\prime \prime}{ }_{\mathrm{nl}}\left[\left(\frac{\sigma_{\mathrm{max}}}{2}\right) / E^{\prime}\right]^{2}
$$

where $\varepsilon_{\max }$ is the maximum strain and $\sigma_{\max }$ is the maximum stress. The arrangement of $E q .3$ gives us:

$$
\Delta T=\left(\frac{\pi L}{K}\right) f\left(\frac{E^{\prime \prime}}{E^{\prime 2}}\right)\left(\frac{\sigma}{2}\right)^{2}
$$

where $\Delta T$ is temperature rise, $K$ is the heat transfer coefficient, and $L$ is the length of the specimen. According to this equation, the temperature variation depends directly on stress.

The moisture content also affects the matrix behavior and consequently the mechanical properties [18] of this composite; it weakens the interface between fiber and matrix $[15,19]$.

In glass fiber reinforced polyamides, mechanical properties depend highly on the orientation and concentration of the fibers [20,21].

As the composite materials are heterogeneous, crack initiation can be induced by a lot of factors. Generally, there are some pre-existing defects in each material that could be generated during the processing and it is impossible to process at an industrial scale, composite with polymer matrix without any micro defects. For this kind of material and especially for unnotched/ nonprecracked specimens, defect initiation represents an important portion of the fatigue total life. It is still a problem to understand the fatigue behavior in case of tests in which the stress is not too high and most of the past studies are about crack propagation [22] which are based on the Paris law [23]. Hence, it is important for researchers to study the crack initiation period.

Bowden and Young [24] have proposed a mechanism on a morphological scale, based on the cavitation phenomenon, for semi-crystalline polymers. According to them, when the stress is applied in the elastic domain, the interlamella separation involves a local variation of volume that can eventually lead to cavities in the amorphous phase. If the stress is applied in the plastic domain, the crystalline phase can also deform. This is the shearing of crystalline lamellae.

Horst [19] studied the plastic deformation in composite and reports: crack initiation occurs in zones where the stress concentration is high, usually at fiber ends where the coupling agent is not much present and it spreads along the walls of the fibers. This cavity formation is particularly affected by the hydrostatic component of stress $[25,26]$. These cavities grow and create an internal tension stress and this stress can promote the formation of new cavities and new areas of debonding between fibers and matrix. Following this debonding, the load passed on to the fiber will be lower; the local stress in the matrix increases and induces the matrix deformation $[19,27]$.
Hertzberg and Manson [10] reported that fatigue damage initiates from debonding of the fibers that are perpendicular to the load axis. All these kinds of defects could happen easily in one heterogeneous matrix and these defects during the fatigue test could constitute weak points. The weak points in the glass fiber reinforced polymer are at the interface between fiber and matrix and the applied load can induce the build-up of cavities.

Many other mechanisms can occur just before the fracture such as fiber debonding, fiber breakage, shear crack formation along fibers, plastic deformation, microcrack and void craze development and coalescence, matrix fracture and crack branching [28].

During fatigue test of these materials under alternative loading, when the initial stress is not too high, the frequency is between 10 and $20 \mathrm{~Hz}$ and the life time is between 10,000 and 500,000 cycles, the microcracks will be formed in the sample under maximum stress. The concentration of the cracks will increase until the fracture. For this part of Wohler curve, one can distinguish three different stages during a fatigue test [29] as follows:

The first stage corresponds to the introduction of a thermal regime associated with reduction of material stiffness. In general, for a fatigue test with a $10 \mathrm{~Hz}$ frequency at room temperature, the number of cycles in this area is $<1,000$ cycles.

The second stage is the period of crack initiation or defect formation. For amorphous polymer like polystyrene [30], the characteristics of the material do not change significantly in this zone. For a small value of the applied load, this period can be very long. For pure polymers, more than $80 \%$ of the lifetime of materials is defined in this second stage. During this period, presites accumulate in most localized area but their effect is only to decrease very slowly the induced stress until they reach a critical concentration [31].

The third zone is a period of coalescence of the cracks, then propagation. The fracture always happens at the end of this zone. Most of the past studies focused on this period and explained the physical and mechanical phenomenon involved in it [30-32].

To have a deep understanding and to clarify the effect of various kinds of applied loads on fatigue crack initiation in glass fibers reinforced polyamides, two kinds of applied loads have been investigated in the present study.

\section{MATERIALS AND EXPERIMENTAL PROCEDURE}

The specimens for fatigue tests were injection moulded from polyamide 66 reinforced with $30 \mathrm{wt} \%$ glass fiber and containing a black pigment ideal for the automotive under hood parts. It was provided by Rhodia, France. Glass fibers were sized with a specific coupling agent for polyamides. The fiber length is between 100 and $300 \mu \mathrm{m}$. Dogbone tensile type specimens according to the ISO 3167 standard with length of $150 \mathrm{~mm}, 10 \pm 0.2$ of small widths, $20 \pm 0.2$ of large width, and $4 \pm 0.2$ thicknesses 


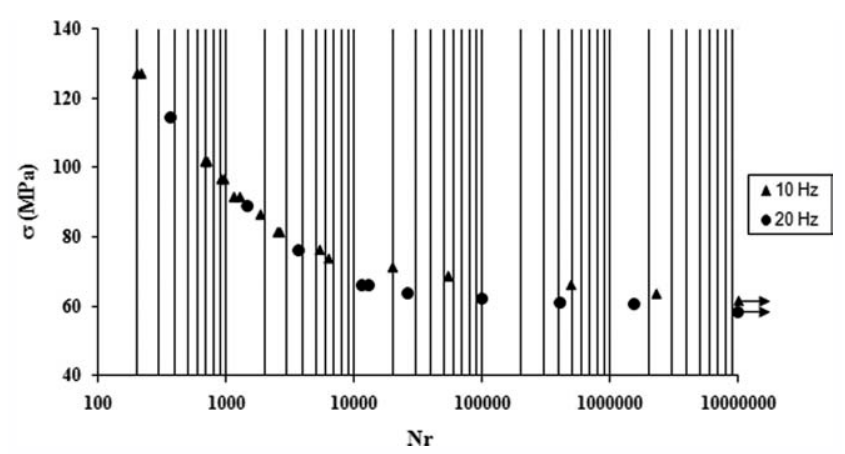

FIG. 1. Wohler curves in TTF tests for the frequencies of 10 and 20 $\mathrm{Hz}, \sigma$ is the applied stress and $\mathrm{Nr}$ is the number of cycles at fracture.

were injection molded from our material. The samples were injected by injection machine DK Codim $175 \mathrm{t}$ press using a fill closed loop system using a holding pressure of $100 \mathrm{MPa}$, the maximum melt temperature of $290^{\circ} \mathrm{C}$, a mold temperature of $80^{\circ} \mathrm{C}$ and a cooling time of $5 \mathrm{~s}$. Young modulus is $E=2040 \pm 185$ (MPa), flexural modulus is $E=8000 \pm 70(\mathrm{MPa})$, and ultimate stresses for tension and flexion test are $\sigma_{\text {Rtension }}=160 \pm 10(\mathrm{MPa})$ and $\sigma_{\text {Rflexion }}=240 \pm 3(\mathrm{MPa})$.

The viscoelastic spectrum was performed at $10 \mathrm{~Hz}$ and temperature varied from -10 to $160^{\circ} \mathrm{C}$ with temperature rise rate of $5^{\circ} \mathrm{C} / \mathrm{min}$, dynamic force of $2 \mathrm{~N}$, and an amplitude of $30 \mu \mathrm{m}$ using D.M.T.A. with three-point bending device. The glass temperature is $T_{\mathrm{g}}=55^{\circ} \mathrm{C}$, it is measured from the maximum point of the curve of loss modulus $\left(E^{\prime \prime}\right)$. Generally this value is close to the one measured by D.S.C. The loss modulus $\left(E^{\prime \prime}\right)$ at $42^{\circ} \mathrm{C}$ is 343 (MPa). The density is $1,409 \pm 13\left(\mathrm{~kg} / \mathrm{m}^{3}\right)$.

The fiber ratio is determined after $3 \mathrm{~h}$ pyrolysis at $700^{\circ} \mathrm{C}$. The fraction crystallinity is $35 \pm 4 \%$. It was measured by Differential Scanning Calorimetry experiment (NETZSCH DSC-Q10) using the ratio $\frac{\Delta H_{m}}{\Delta H_{m}^{c}}$ where $\Delta H_{\mathrm{m}}$ is the experimental value of melting enthalpy and $\Delta H_{\mathrm{m}}^{c}$ the melting enthalpy of the $100 \%$ crystalline polymer, $\Delta H_{\mathrm{m}}^{c}=192 \mathrm{~J} / \mathrm{g}$ [33].

All mechanical tests were performed at $24^{\circ} \mathrm{C}$ and at relative humidity of $50 \%$ (air-conditioned room) and the specimen contains $0.1 \%$ of water. Tensile and flexion properties were carried out with Instron 5881 machine with $10 \mathrm{KN}$ load cell. Fatigue tests were conducted using a uniaxial, hydraulic, digital-controlled fatigue MTS 830 elastomer test system machine (tension-tension fatigue, TTF test, $R=0.1$ or 0.3 ) and an alternative bending device (alternative flexural fatigue, AFF test, $R=-1$ ) at frequencies ranging between 2 and $60 \mathrm{~Hz}$. The amplitude choice depends on the performance of the machine and the dimensions of specimen. The AFF test is conducted by applying strain on the specimens. The self-heating temperatures of fatigue tests were measured in specific area (maximum temperature) by infrared thermometer (Raynger-MX4). Observation under an optical microscope shows that the majority of the fibers are oriented in the direction of injection, even in the core of the sample [18].

The fracture surfaces were analyzed by Hitachi S-4800 Scanning Electron Microscope (SEM) with a potential acceleration of $0.8 \mathrm{KV}$.

\section{RESULTS AND DISCUSSION}

\section{Wohler Curves}

The Wohler curves obtained from TTF and AFF tests for the frequencies of 2,10, and $20 \mathrm{~Hz}$ are shown in Figs. 1 and 2. The following comments can be made with the results obtained from these graphs:

Effect of Loading Amplitude. In all curves, one can generally distinguish two different zones related to the high (Zone-I) and low loading amplitude (Zone-II). In Zone I, the curves for different frequencies are nearly superimposed and there is no significant difference between 10 and $20 \mathrm{~Hz}$ Wohler curves. These two frequencies have the same effect on fatigue behavior of the sample. For TTF test, this zone corresponds up to $10^{4}$ cycles. For AFF tests, there is practically no difference between the curves of 2 and $10 \mathrm{~Hz}$. These two curves are perfectly superimposed, but the Wohler curve obtained with $20 \mathrm{~Hz}$ starts deviating with respect to the other two frequencies from $10^{3}$ cycles onward. At the end of the Zone-I, the two curves start deviating. Figure 3 shows applied strain versus number of cycles to failure in AFF tests.

Bellemare [27] divided the Wohler curve for polyamide 6 nano composite in two regimes. The first part called high-stress regime or thermal regime (when the stress is high and fatigue life is $<200,000$ cycles) and the second part called mechanical regime (when the stress is high and fatigue life is $>200,000$ cycles).

Effect of Frequency. For the two types of tests (TTF and AFF), in Zone-II, the curve corresponding to the 10 $\mathrm{Hz}$ frequency is located above the one which corresponds

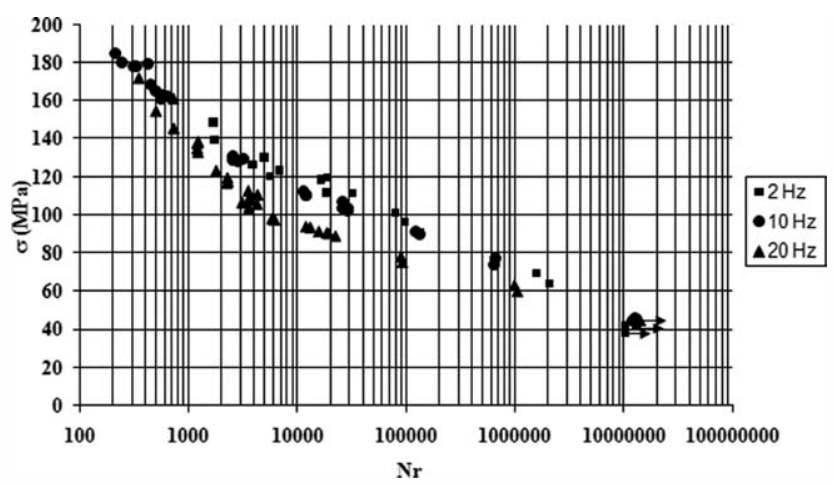

FIG. 2. Wohler curves in AFF tests for frequencies of 2, 10, and 20 $\mathrm{Hz}, R=-1$. 


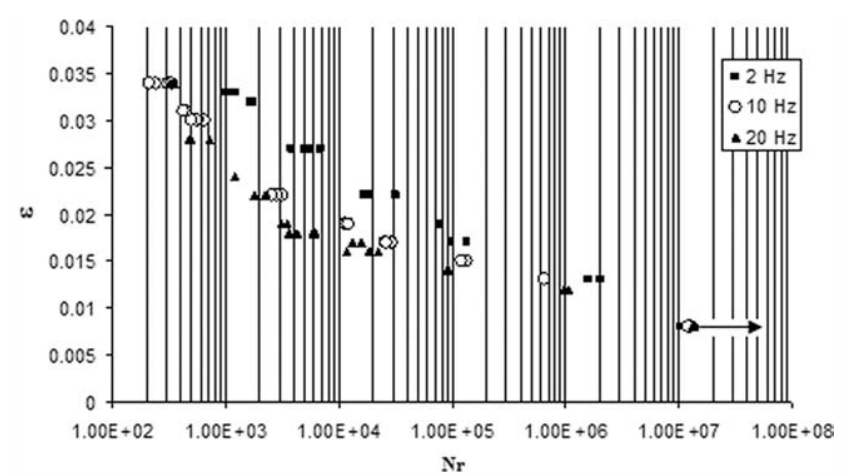

FIG. 3. Applied stress in AFF tests versus number of cycles to failure.

to the $20 \mathrm{~Hz}$ one. On the other hand, the lifetime of the sample tested at $20 \mathrm{~Hz}$ is smaller than the one tested at $10 \mathrm{~Hz}$. For the same initial induced stress, the number of cycles in fracture with a $20 \mathrm{~Hz}$ frequency is smaller than the one for $10 \mathrm{~Hz}$ and this difference is significant when the initial induced stress decreases. In the case of AFF tests, this difference is not very clear between 2 and 10 Hz. However, for all cases, the frequency has a determinant role in lifetime of the sample and an increasing frequency decreases the lifetime [34, 35]. This phenomenon, in fact, is owing to the self-heating during fatigue test (Fig. 4). As one can observe, there is not a significant change in the temperature up to 500 cycles. The temperature increases rapidly from room temperature to $55^{\circ} \mathrm{C}$ up to 4,000 cycles. It remains practically constant up to 20,000 cycles; it continues to increase till $62^{\circ} \mathrm{C}$ before the fracture. It is interesting to study the change in stress. It varies similarly to the temperature curve but in the opposite direction. The first fall of stress is in the zone where the temperature increases which corresponds to self-heating. This zone corresponds to the glass transition zone of composite. Before this zone, the amorphous phase is in glassy state and after this zone it is in rubbery state. The fall of stress in this zone corresponds to this change of physical state. To show the role of frequency, the temperature variation of the specimen surface was measured during the test with 10 and $20 \mathrm{~Hz}$ (TTF) and with 2, 10, and $20 \mathrm{~Hz}$ (AFF) for almost the same number of cycles at fracture (that means under the same level of loading). The

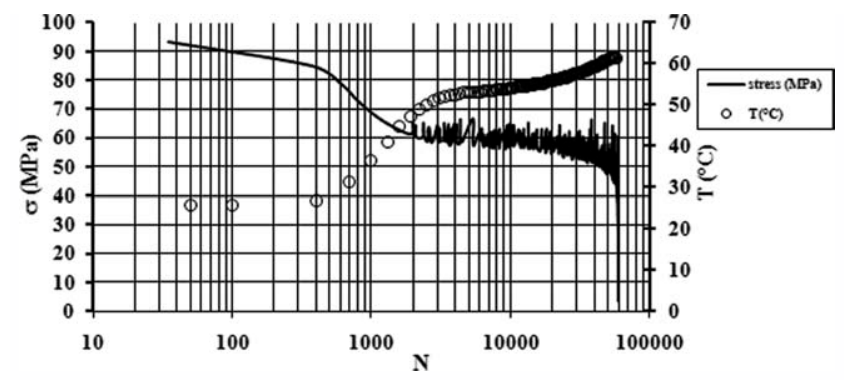

FIG. 4. Induced stress and surface temperature of a PA66/GF sample tested at $10 \mathrm{~Hz}$ in $\operatorname{AFF} \varepsilon_{0}=0.017$, versus the number of cycles.

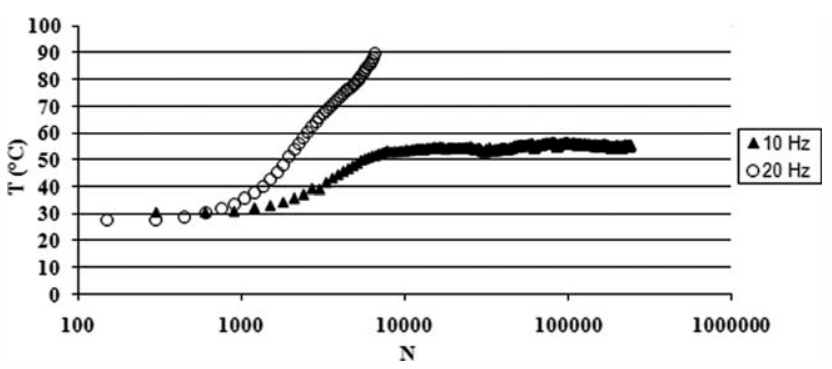

FIG. 5. Surface temperature of a PA66/GF sample tested in TTF at 10 and $20 \mathrm{~Hz}, \sigma_{0}=66 \mathrm{MPa}$ versus the number of cycles.

results are shown in Figs. 5 and 6. One can clearly see that self-heating is more pronounced for 20 than $10 \mathrm{~Hz}$ for two types of tests. For TTF test, the temperature rises from room temperature up to $55^{\circ} \mathrm{C}$ when the frequency is $10 \mathrm{~Hz}$ but when the later is $20 \mathrm{~Hz}$, it increases up to $90^{\circ} \mathrm{C}$ before fracture. For AFF test, we can see the same tendency. During this type of test, self-heating is not prominent when the frequency is $2 \mathrm{~Hz}$. The temperature increase is only equal to $10^{\circ} \mathrm{C}$ before the fracture. Previous experience has shown that when the glass fibers are uncoated, the temperature rise is significantly higher even at a frequency of $10 \mathrm{~Hz}$ [35].

Effect of Type of Loading. By comparing the Wohler curves in AFF and TTF tests for two frequencies, one can show that the shape of the curves is not the same (Fig. 7). The shape of Wohler curves changes with respect to the change in the stress direction. For the same frequency, the curve obtained by TTF test is below the one obtained by AFF test. For higher values of stress, the difference between two curves is very important. But they have practically the same endurance limit. The curves come closer for lower values of stress. To understand the reason why the Wohler curves join in TTF and AFF test, the surface temperature was measured during both tests involving almost the same number of cycles at break, $10^{4}$ and $10^{6}$ cycles (Figs. 8 and 9). The comparison of temperature rise in Fig. 8 shows that for the same fracture number of cycles, the increase in self-heating temperature in TTF

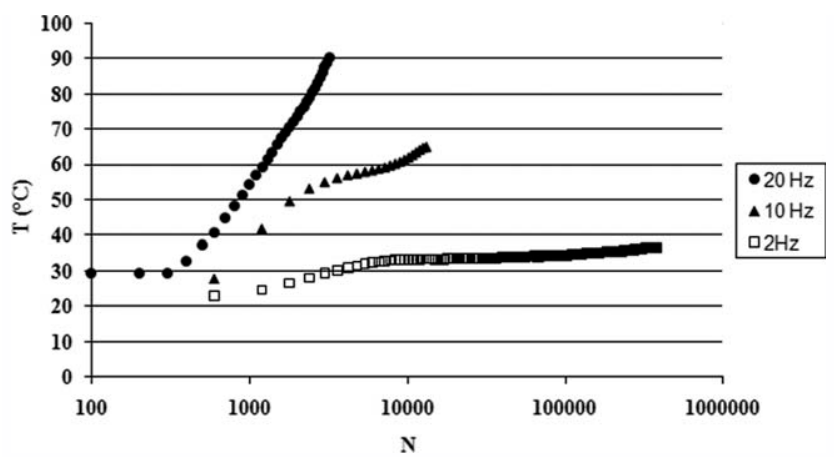

FIG. 6. Surface temperature variation during AFF tests at 2, 10, and 20 $\mathrm{Hz}$, correspond to $\varepsilon_{0}=0.019$. 


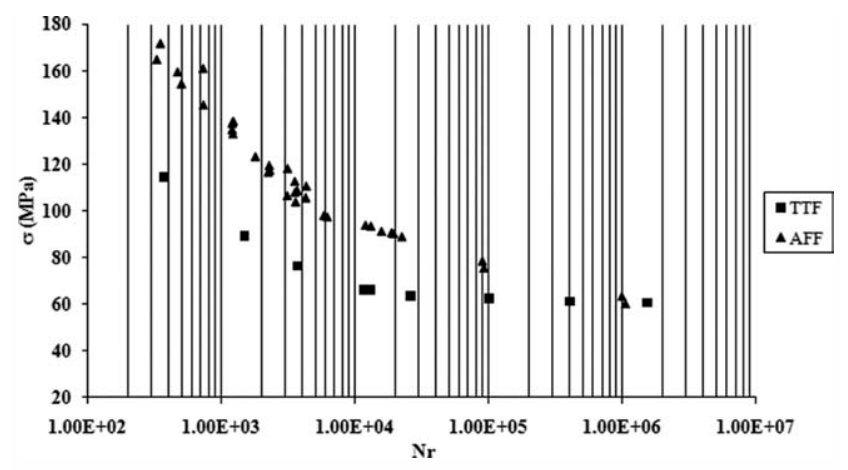

FIG. 7. Wohler curves at $20 \mathrm{~Hz}$ in TTF and AFF tests.

test is higher than in AFF test. In this zone, the stress in TTF test is smaller than the stress in AFF test. In general, for both Wohler curves when the value of stress increases, the self-heating temperature also increases. For the endurance limit (without fracture), there was no increase of temperature and there was no damage in the surface. As it refers to the comparison of stress in two directions and as in TTF test all fiber-matrix interphases are involved, the self-heating temperature is greater than the one in AFF test. They start to increase in the same way until 2,000 cycles and after that, these two curves separate and for two frequencies (10 and $20 \mathrm{~Hz}$ ) the results obtained are the same.

Figure 9 shows that there is a lag between two curves because of the little difference between the values of stress $\left(\sigma_{\mathrm{T}-\mathrm{T}}=66, \sigma_{\mathrm{F}-\mathrm{A}}=74\right)$. In the joining point of both curves, when the value of stress is nearly the same, the self-heating temperatures increases in a similar way and the values of these temperatures are almost the same. After the joining point, there is no fracture in the specimens until $10^{7}$ cycles. Indeed, the temperature rise depends on different parameters such as frequency and loading amplitude.

Figure 6 also shows this dependence; the surface temperature increases by following the same trend. In fact, in TTF test, the matrix located between fibers parallel oriented to the applied load, is more involved than in AFF test. For AFF test, these are the interfaces between fiber and matrix which are the most involved. To enhance the reasoning, the AFF test of polyamide 66 without additives

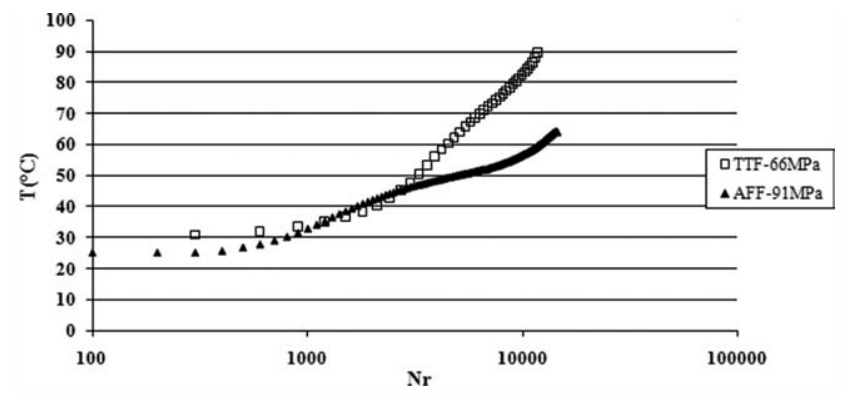

FIG. 8. Increasing surface temperature for two fatigue tests performed in $\operatorname{TTF}\left(\sigma_{\max }=66 \mathrm{MPa}\right)$ and $\operatorname{AFF}\left(\sigma_{\max }=91 \mathrm{MPa}\right)$ tests at $20 \mathrm{~Hz}$.

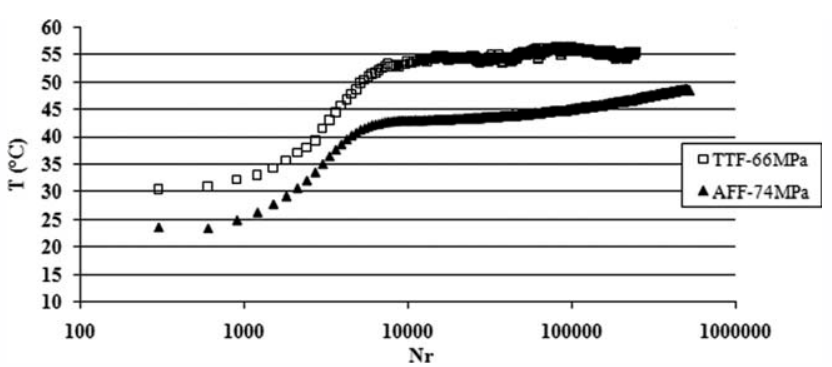

FIG. 9. Increasing surface temperature for two fatigue tests performed in $\operatorname{TTF}\left(\sigma_{\max }=66 \mathrm{MPa}\right)$ and $\operatorname{AFF}\left(\sigma_{\max }=74 \mathrm{MPa}\right)$ at $10 \mathrm{~Hz}$.

(matrix) is carried out and Wohler curve is compared with that composite (Fig. 10). As we can see in the Wohler curve of PA 66, after six $10^{5}$ cycles, the plateau was observed and this zone is nearly the same for Wohler curve in TTF test.

\section{Self-Heating}

To understand the effect of frequency on life time and the role self-heating, different TTF tests are performed at various frequencies (Fig. 11). The temperature for the frequencies from 30 to $60 \mathrm{~Hz}, R=0.3$ keeps on increasing indefinitely until fracture. At $20 \mathrm{~Hz}$, it increases until $45^{\circ} \mathrm{C}$ and after that, it remains stable until $10^{7}$ cycles. In this test, there was no fracture before $10^{7}$ cycles. As shown in Fig. 11, the temperature rise is faster with an increasing frequency. At $60 \mathrm{~Hz}$, the life time is short and it is governed by thermal fatigue, between 50 and $30 \mathrm{~Hz}$ the number of cycles at break decreases linearly with an increasing frequency but the maximum temperature is stable between 60 and $40 \mathrm{~Hz}$. For the high frequencies, a coupling effect of thermal fatigue and mechanical fatigue was observed, Fig. 12; but for low frequencies, it exists just as an effect of mechanical fatigue.

\section{Fractography by SEM}

With an aim of comparing fatigue tests in two directions, the fracture surfaces have been observed by scanning electron microscope. The number of cycles in frac-

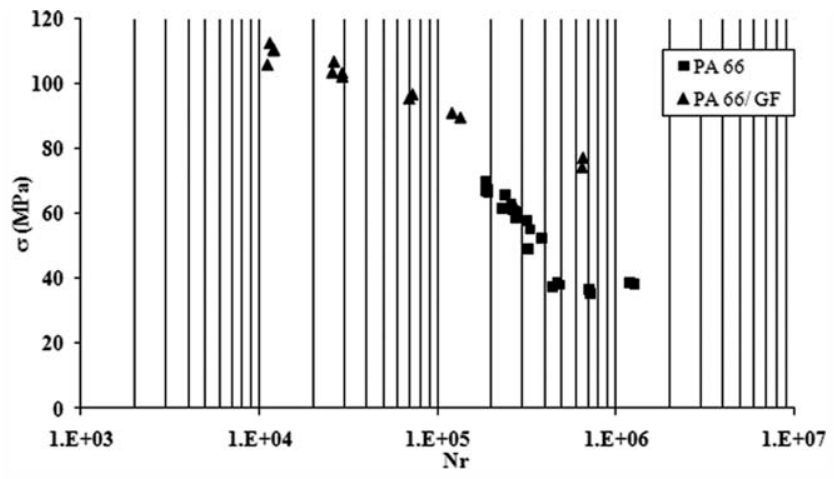

FIG. 10. Wohler curves of PA 66 and PA66/GF in AFF tests at $10 \mathrm{~Hz}$. 


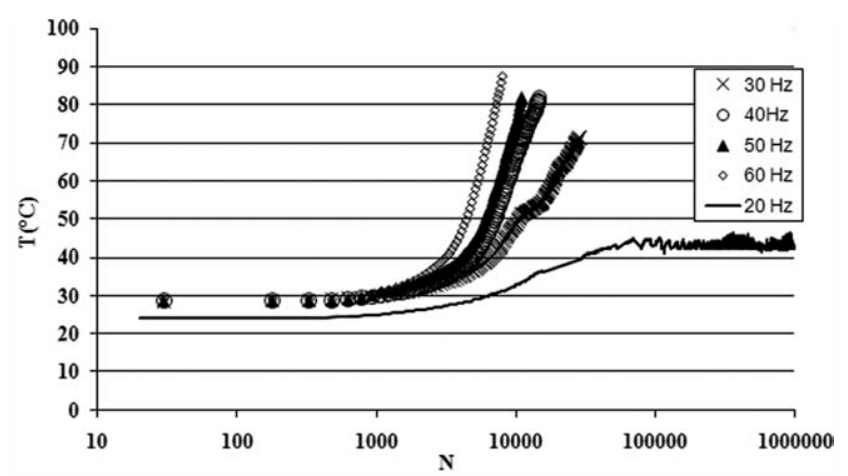

FIG. 11. Surface temperature variation induced by self-heating during TTF test, $\sigma_{\mathrm{Max}}=72 \mathrm{MPa}-\sigma_{\mathrm{Min}}=21 \mathrm{MPa}(R=0.3)$ at various frequencies $(20-60 \mathrm{~Hz})$.

ture is nearly the same and hence it is the same area in Wohler curves. Figure $13 \mathrm{a}$ and $\mathrm{b}$ shows the fracture surface of specimen in TTF test. In fractography of surface in TTF test, different areas are distinguished; bared fibers surounded by matrix show the good properties of fiber/ matrix interface, matrix plastic deformation and broken fibers. For this test, the surface temperature increases until $90^{\circ} \mathrm{C}$. The fracture surface after a fatigue test shows that the matrix is around the bared fibers. The reason being the rise in self-heating temperature which allows the matrix to reach the rubbery state. In the rubbery state, the molecular motion will increase, the modulus decreases, and the matrix becomes softer and in coalescence stage it remains around the fibers.

Figure 14 shows the tensile test in room temperature (a) and $90^{\circ} \mathrm{C}$ (b): When the static test is carried out at room temperature, the matrix does not remain around the fibers and we observe a brittle fracture (Fig. 14a). As shown in Fig. 14a, there is just a part of matrix in root fibers and there is no interphase. The matrix cracks have a brittle behavior and there is no surface temperature rise during the test. After a tensile test at $90^{\circ} \mathrm{C}$, we observed a ductile fracture (Fig. 14b). As shown in Fig. 14b, when

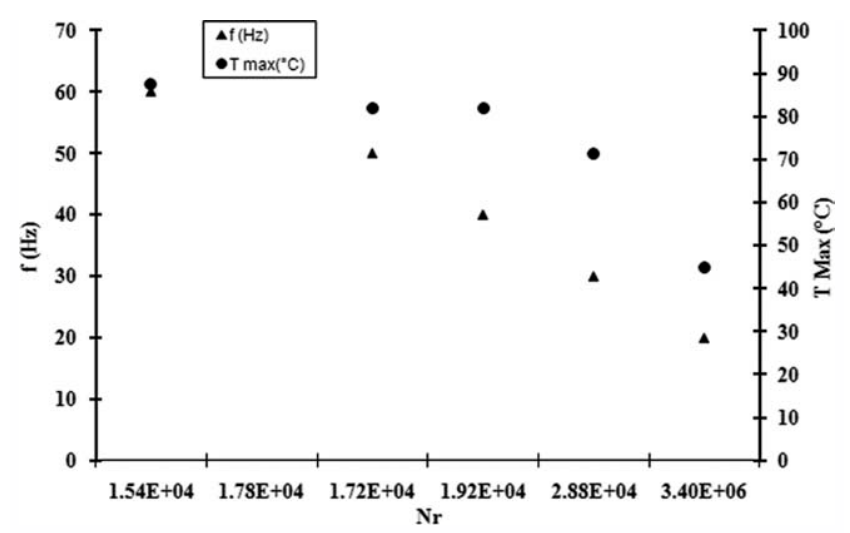

FIG. 12. Frequency variation $(20-60 \mathrm{~Hz})$ and maximum temperature versus the number of cycles at fracture, $\sigma_{\mathrm{Max}}=72 \mathrm{MPa}-\sigma_{\mathrm{Min}}=21 \mathrm{MPa}$ $(R=0.3)$.
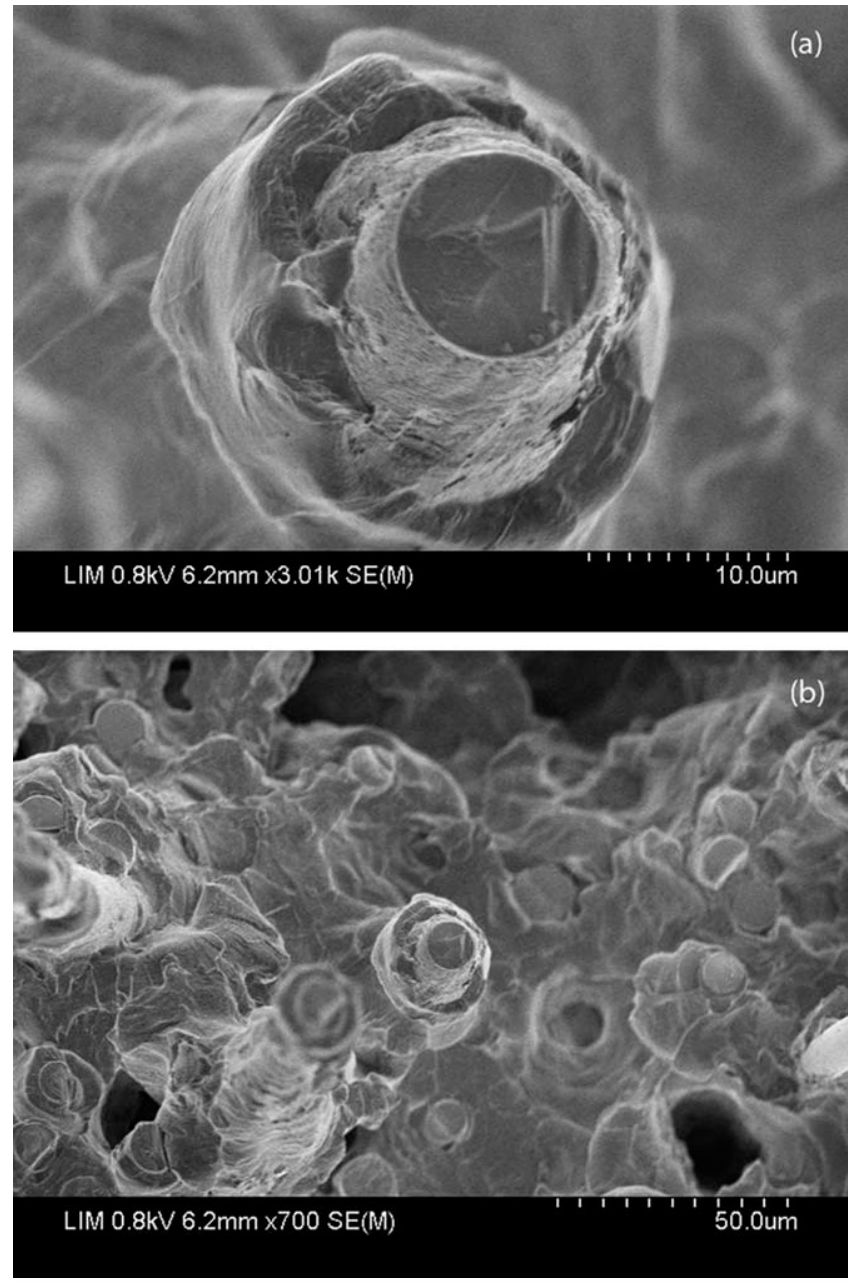

FIG. 13. (a) SEM of fatigue failure surface in the subskin position of a sample tested in TTF at $20 \mathrm{~Hz}, \sigma_{\max }=66 \mathrm{MPa}, 10 \mu$ scale. Sheath of matrix is observable around the fiber. (b) SEM of fatigue failure surface of a same sample tested as in (a) (TTF at $\left.20 \mathrm{~Hz}, \sigma_{\max }=66 \mathrm{MPa}\right) 50 \mu$ scale.

tensile test is performed at $90^{\circ} \mathrm{C}$ the matrix is in rubbery state, and hence it will be souronding the fibers and the thickness is between 30 and $45 \mu \mathrm{m}$. Figure 15 shows the fracture of the surface in AFF test; several areas are distinguished: streaks in the matrix owing to the effect of fatigue test, broken fibers, pulled out fibers, and cavities appear around the fibers (Fig. 15a). The surface temperature in this test increases until $70^{\circ} \mathrm{C}$. In $\mathrm{AFF}$ test too, the self-heating temperature allows the matrix to reach a rubbery state but the matrix does not remain around the fibers.

\section{CONCLUSION}

The Wohler curves display two zones related to the high (Zone I) and low loading amplitude (Zone II). In Zone I, the curves for various frequencies are nearly superimposed, whereas in Zone II the curve location is lower when the frequency increases. For the same maxi- 
mum induced stress, the lifetime is smaller when the frequency increases, owing to the self-heating effect. The shape of the Wohler curve in AFF test is different from the one of the TTF test. It changes with the change in loading direction, owing to the glass fiber orientation in the specimen. As the glass fibres are oriented parallel to the loading direction, all the matrix/glass fiber interfaces are involved in TTF tests but it is not the case for AFF test. In tension-tension loading, the matrix is much more stressed and that is the reason why the shape of the Wohler curves looks like the Wohler curve of the neat matrix. For a same number of cycles at break, the temperature rise induced by self-heating is higher in TTF test than in AFF test. The self-heating effect has been studied by tension-tension tests with frequencies ranging between 20 and $60 \mathrm{~Hz}$. For low frequencies, there is only an effect of the mechanical loading and for high frequencies a coupling effect of mechanical and thermal fatigue is observed. The failure surface of samples tested in TTF displays bared fibers surrounded by matrix (which demonstrates the good interface quality), the plastic deformation of the matrix and broken fibers. In AFF test, the self-heat-
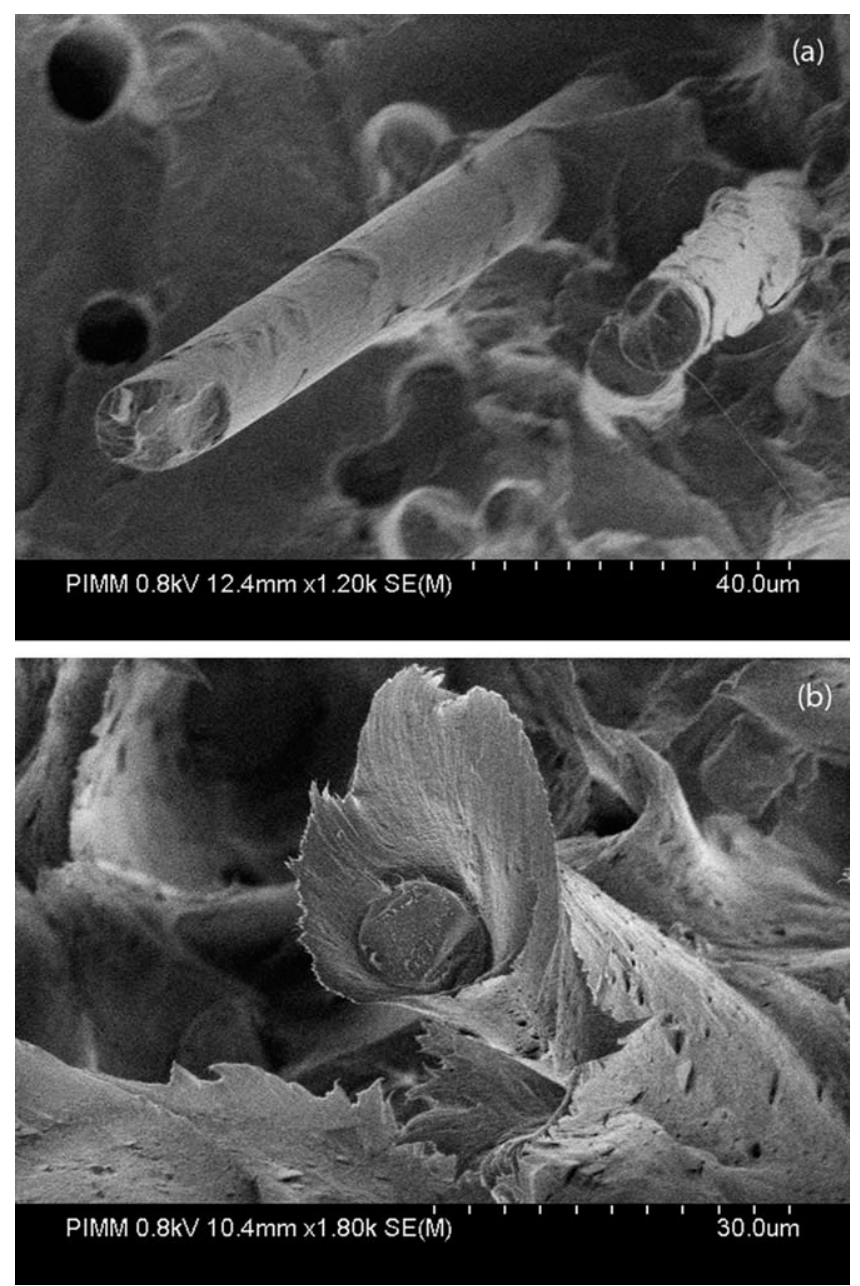

FIG. 14. (a) SEM of the failure surface after a tensile test at room temperature. (b) SEM of the failure surface after a tensile test at $90^{\circ} \mathrm{C}$.
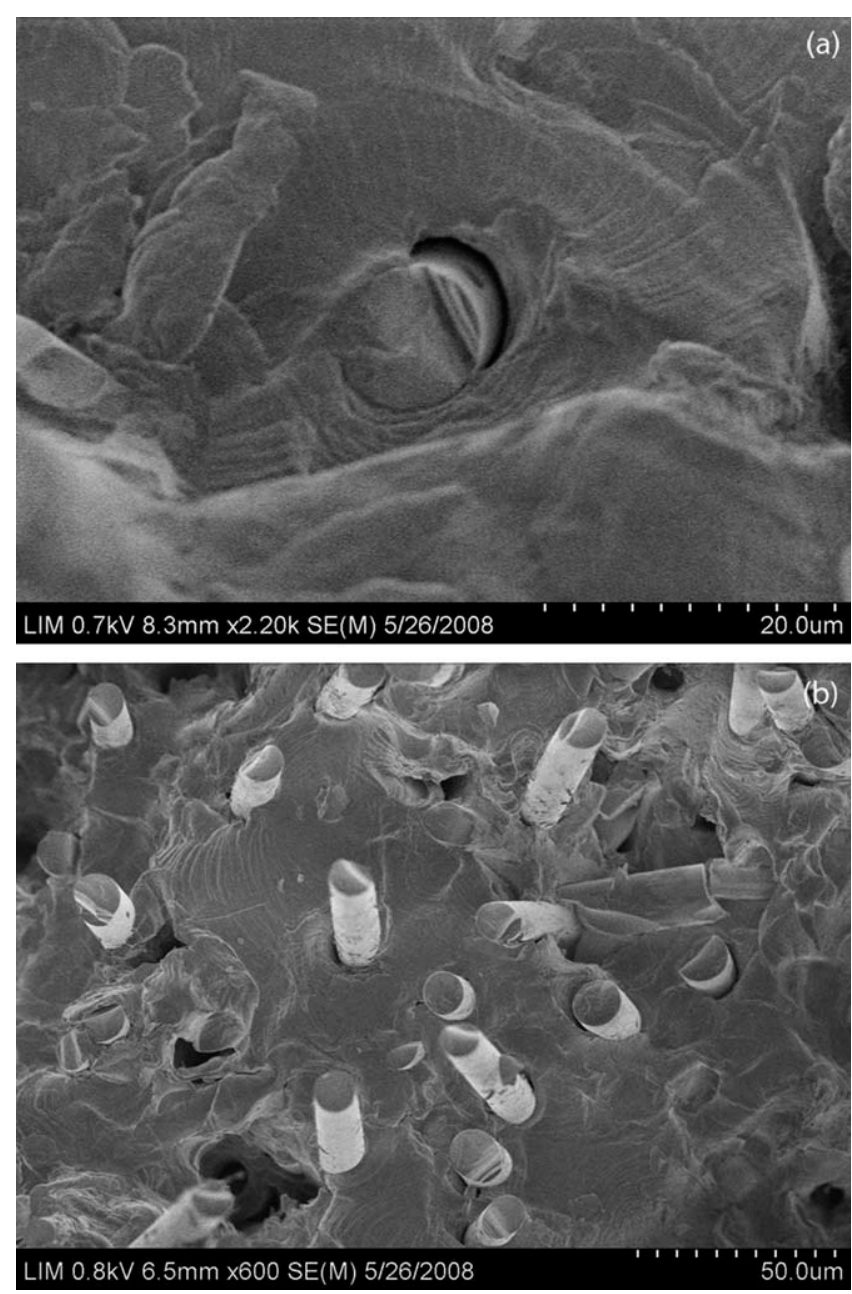

FIG. 15. (a) SEM of fatigue failure surface in the subskin position of a sample tested in AFF at $10 \mathrm{~Hz}, \varepsilon_{0}=0.017, \sigma_{\max }=102 \mathrm{MPa}, 20 \mu$ scale. (b) SEM of fatigue failure surface (core position) of a sample tested in $\mathrm{AFF}$ at $10 \mathrm{~Hz}, \varepsilon_{0}=0.017, \sigma_{\max }=102 \mathrm{MPa} 50 \mu$ scale.

ing temperature allows the matrix to reach a rubbery state but the matrix does not remain around fibers.

\section{ACKNOWLEDGMENTS}

The authors specially thank Dr. Gilles Robert and Rhodia, France for supplying the neat matrix Polyamide 66 and the compound of Polyamide 66 reinforced with $30 \%$ glass fibers.

\section{ABBREVIATIONS}

AFF Alternative flexural fatigue

TTF Tension-tension fatigue

\section{REFERENCES}

1. A.T. DiBenedetto and G. Salee, Polym. Eng. Sci., 19, 512 (1979).

2. B. Mouhmid, A. Imad, N. Benseddiq, S. Benmedakhène, and A. Maazouz, Polym. Test., 25, 544 (2006). 
3. J.L. Broge, Auto. Eng., 108, 70 (2000).

4. B. Mouhmid, A. Imad, N. Benseddiq, and D. Lecompte, Comp. Sci. Technol., 69, 2521 (2009).

5. M. Beghini, L. Bertini, and P. Forte, Comp. Sci. Technol., 66, 240 (2006).

6. A. Bernasconi, P. Davoli, A. Basile, and A. Filippi, Int. J. Fatigue., 29, 199 (2007).

7. Y. Zhou and P.K. Mallick, Polym. Comp., 27, 230 (2006).

8. J. Karger-Kocsis and K. Friedrich, Plast. Rubb. Process Appl., 12, 63 (1989).

9. R.W. Lang, J.A. Manson, and R.W. Hertzberg, The Role of the Polymeric Matrix in the Processing and Structural Properties of Composite Materials, J.C. Seferis and L. Nicolais, Eds., Plenum Press, New York, 377 (1983).

10. R.W. Hertzberg and J.A. Manson, Fatigue of Engineering Plastics, Academic Press, New York, 269 (1980).

11. J.P. Trotignon and A. Tcharkhtchi, Macromol. Symp., 108, 231 (1996).

12. D.O. Stalnaker and W.W. Stinchcomb, In Composite Materials: Testing and Designs, 5th Conference, ASTM STP 674, ASTM, 620 (1979).

13. M.G. Wyzgoski, G.E. Novak, and D.L. Simon, J. Mater. Sci., 25, 4501 (1990).

14. K. Handa, A. Kato, and I. Narisawa, J. Appl. Polym. Sci., 72, 1783 (1999).

15. J.J. Horst and J.L. Spoormaker, Polym. Eng. Sci., 36, 2718 (1996).

16. C.M. Sonsino and E. Moosbrugger, Int. J. Fatigue, 30, 1279 (2008).

17. T. Kajiyama and A. Takahara, J. Japan Rub. Ind. Ass., 59, 34 (1986).

18. S. Barbouchi, V. Bellenger, A. Tcharkhtchi, Ph. Castaing, and T. Jollivet, J. Mater. Sci., 42, 2181 (2007).
19. J.J. Horst and J.L. Spoormaker, J. Mater. Sci., 32, 3641 (1997).

20. A. Bernasconi, P. Davoli, A. Basile, and A. Filippi, Int. J. Fatigue., 29, 199 (2007).

21. Y. Zhou and P.K. Mallick, Polym. Compos., 27, 230 (2006).

22. J. Karger-Kocsis, Composites, 21, 243 (1990).

23. P.C. Paris and F. Erdogan, J. Bas. Eng. Trans. ASME Ser D, 85, 528 (1963).

24. P.B. Bowden and R.d. Young, J. Mater. Sci., 9, 2034 (1974).

25. H.H. Kausch, Polymer Fracture, Springer, Berlin, 456 (1987).

26. E.J. Kramer, Adv. Polym. Sci., 52-53, 1 (1983).

27. S.C. Bellemare, M.A. Bureau, J. Denault, and J.I. Dickson, Polym. Comp., 25, 433,2004.

28. R.W. Lang, J.A. Manson, and R.W. Hertzberg, J. Mater. Sci., 22, 4015 (1987).

29. W. Van Paepegem and J. Degrieck, Int. J. Fatigue, 24, 747 (2002).

30. F. Baltenneck, J.P. Trotignon, and J. Verdu, Polym. Eng. Sci., 37, 1740 (1997).

31. J.P. Trotignon and J. Verdu, "Rupture en fatigue des matériaux polymères," in Introduction à la mécanique des polymères, C. G'sell and J.M. Haudin Eds, INPL, p 413 (1995).

32. M.T. Takemori, R.P. Kambour, and D.S. Matsumoto, Polym. Commun., 24, 297 (1983).

33. J.E. Mark, Polymer Data Handbook, Oxford University Press, New York, 195 (1999).

34. M.T. Hahn R.W. Hertzberg, J.A. Manson R.W. Lang, and P.E. Bretz, Polymer, 23, 1675 (1982).

35. V. Bellenger, A. Tcharkhtchi, and Ph. Castaing, Int. J. Fatigue, 28, 1348 (2006). 